\title{
Assessment of critical success factors of business process re-engineering in the Nigerian oil and gas industry
}

\author{
U.O. Asikhia ${ }^{a *}$ and D.O. Awolusi ${ }^{b}$ \\ a Department of Business Administration and Marketing, Babcock Business School, Babcock University, \\ Ilishan-Remo, Ogun State; P.M.B 21244, Ikeja, Lagos, Nigeria. \\ ${ }^{\mathrm{b}}$ University, Ilishan-Remo, Ogun State; P.M.B 21244, Ikeja, Lagos, Nigeria. \\ *To whom all correspondence should be addressed \\ olalekanasikhia@yahoo.com; asikhiao@babcock.edu.ng
}

\begin{abstract}
Business Process Re-engineering (BPR) is defined as the critical analysis and radical redesign of existing business processes to achieve breakthrough improvements in performance measures like cost, quality, speed, profitability and services. The purpose of this paper is to identify the critical success factors of BPR implementation, to evaluate their effects on the primary measures as expressed by the operational performance and the secondary measures as expressed by the organizational performance, and to find out the effect of the operational performance on the organizational performance of Nigerian oil and gas companies. To achieve these objectives, an empirical study was conducted via the administration of 650 self-administered copies of questionnaire to a randomly selected senior and management staff of eight (8) re-engineered Oil and Gas Companies in Nigeria. Using the framework from Khong \& Richardson (2003), factors manifesting operational performance and organizational performance were regressed on the Critical Success Factors (CSFs) manifesting successful BPR. Findings based on the survey revealed that successful BPR can positively affect both operational and organizational performance measures in the Nigerian oil and gas companies.
\end{abstract}

\section{Introduction}

With the rapid globalization of production and markets world-wide, oil and gas companies are faced with a changing competitive environment. They are creating the conditions that will enable them to be competitive in both domestic and international markets. Accordingly, oil and gas companies seek to adopt and implement a set of operations management practices/techniques that have been successful elsewhere and that will help them to identify changes in their environment and to respond proactively through radical improvement (Ozcelik, 2010; Khodakaram, Mohammad \& Ahmad, 2010; Salaheldin, 2009). One of such management practices/ techniques is Business Process Re-engineering (BPR), which has received great attention in the last two decades (Ozcelik, 2010; Siha \& Saad, 2008; Singh \& Kant, 2008; Vergidis, Tiwari \& Majeed, 2008; Bhatt, 2000; Khodakaram et al., 2010; Al-Mashari, Irani \& Zairi 2001; Abdolvand Albadvi \& Ferdowsi, 2008; Adeyemi \& Aremu, 2008).

Companies use BPR to improve performance substantially on key processes that impact customers and organizational performance (Abdolvand et al., 2008). For example, BPR can serve as a veritable tool for costs and cycle times reduction, by eliminating unproductive activities and the employees who perform them (Ozcelik, 2010). In addition, BPR improves quality by reducing the fragmentation of work and establishing clear ownership of processes, hence, workers gain responsibility for their output and can measure their performance based on prompt feedback (Al-Mashari et al., 2001). In addition, BPR has great potential for increasing productivity through reduced process time and cost, improved quality, and greater customer satisfaction, but it often requires a fundamental organisational change. As a result, the implementation process is complex, and needs to be checked against several success/failure factors to ensure successful implementation (Ozcelik, 2010; Siha \& Saad, 2008; Singh \& Kant, 2008; Vergidis et al., 2008; Bhatt, 2000).

The oil and gas industry has been transformed by a number of fundamental changes (Cabin \& Grant, 1996) in the past two decades. Between 1990 to date, almost the entire world's oil majors- both old and new, underwent farreaching re-engineering, which often involved radical simultaneous changes in strategy and organizational structure in a compressed time-frame (Cabin \& Grant, 1996; Abdolvand et al. 2008). In addition, recent downturn across the globe has created perfect environment for BPR implementation in the Nigerian oil and gas industry.

However, despite the significant growth of the BPR concept, not all organisations embarking on BPR projects achieve their intended result. Hammer \& Champy (1993), Abdolvand et al. (2008), Adeyemi. \& Aremu (2008), and Ozcelik (2010) estimate that as many as 50-70 percent do not achieve the dramatic results they seek. This is attributed to poor implementation of BPR rather than a problem with the concept itself (Siha \& Saad, 2008; Singh \& Kant, 2008; Vergidis et al., 2008; Jarrar \& Aspinwall, 1999). Such contradictory outcomes of not good result obtained from a 
process that has been adjudged to be good raise concerns among companies evaluating BPR as a crucial strategic initiative (Ringim, Razalli \& Hasnan, 2011). Al-Mashari \& Zairi (1999) thus offer a unique opportunity for conducting studies oriented to identify critical factors that can influence the success of BPR implementations. Most significantly, the mixture of results made the issue of BPR implementation very important (Bhatt, 2000; Abdolvand et al., 2008; Shin \& Jemella, 2002; Siha \& Saad, 2008; Singh \& Kant, 2008; Vergidis et al., 2008). Hence, based on the analysis of past researches, the purpose of this paper is threefold: Firstly, to identify the CSFs of BPR implementation efforts in the Nigerian oil and gas industry; secondly, to evaluate the effects of the BPR CSFs on the operational and the organizational performances of the Nigerian oil and gas companies; and finally, to examine the effects of the operational performance (primary measures) on the organizational performance (secondary measures).

This study was motivated by the submissions of Al-Mashari \& Zairi (1999), Ahmed, Francis \& Zairi (2007) and Khong \& Richardson (2003). According to Al-Mashari \& Zairi (1999), despite the significant investments in BPR initiatives made by organizations around the world, formal efforts to determine their success and the underlying causes have been very limited. Contending with the measurement of business performance, which often focused on financial metrics, Khong \& Richardson (2003) specifically identified this gap in the literature, on the premise that many researchers often use objective measures such as turnover and profit as a form of measuring enterprise/business performance. However, according to Khong \& Richardson (2003), perceived measures can replace objective measures of business performance. Lastly, Ahmed, Francis \& Zairi (2007) posit that much effort is needed in developing a model for BPR and its critical success factors (CSFs) should be considered for private and public organizations.

\section{Review of relevant literature}

Thus far, much has been written on BPR and its importance in improving the performance of services and manufacturing industries in developed and emerging economies. Literature on BPR implementation suggests that the BPR practices are positively associated with organizational performances (Ringim et al., 2011; Adeyemi \& Aremu, 2008; Ahmed et al., 2007 ; Khong \& Richardson, 2003). However, a review of the current literature on BPR practices indicated that much have been written about BPR implementation in large manufacturing and service firms in developed economies, but little attention has been paid to their implementation in developing economies, like Nigeria (Khong \& Richardson, 2003). Specifically, most of previous studies have been done on the impact of BPR practices on firm's performances in Europe, USA and the Far East (Ozcelik, 2010; Siha \& Saad, 2008; Smith, 2003; Ascari, Rock \& Dutta, 1995). In contrast, few, if any, previous writers have analysed BPRperformance relationships of oil and gas companies in developing economies (Cibin \& Grant, 1996). In a similar vein, there is a dearth of literature regarding the impact of
BPR implementation on performance of oil and gas companies (Ringim et al., 2011; Al-Mashari et al., 2001; Cibin \& Grant, 1996). Furthermore, it has been pointed out about the lack of consistency in research in BPR due to the absence of standard and universally acceptable measurement model and instrument. Thus, there is a stringent necessity to provide a model that amalgamates BPR enablers with BPR effectiveness and BPR success (Ahmed et al., 2007).

In this study, an empirical framework was created to assess the impact of critical success factors of BPR on business performance. When the BPR implementation effort is successful, customers are likely to be satisfied with their products or services. Furthermore, customers are also likely to be satisfied with the customer services offered by a company. In addition, a successful BPR effort can also enable oil and gas companies to better manage its operational performance and the consequential increases in organizational performance. In specific terms, a successful BPR can lead to Organisational growth and sustainable competitive advantage, in relation to competitors in the industry. Overall, staff and other stakeholders are motivated to improve their value additions towards the realization of the strategic objectives of the Organization. Given the above submissions, it is pervasive that successful BPR efforts should result in positive organizational performance (Abdolvand et al., 2008; Khong \& Richardson, 2003; Cabin \& Grant, 1996).

Many studies have dealt with the CSFs of BPR, including Peppard \& Fitzgerald (1997), Al-Mashari \& Zairi (1999) and Ahmed et al. (2007). By considering a few definitions given by previous authors, CSFs is defined as the few things which must go right for the BPR to happen successfully (AlMashari \& Zairi, 1999). From the research by Berrington \& Oblich (1995), it could be summarised that in order to implement reengineering, an organisation needs to understand its structure first, before successful implementation could be accomplished. Another important point is that commitment needs to be maintained and enhanced through communication. The people issue rather than the technology issue is seen as important to be dealt with and managed in order to make the change effort a success. This is essential as people are often resistant to change, as such, for any success to be achieved there is need for adequate orientation to ensure a fit. In the same vein management efficiency, organizational structure, EPR planning and management as well as information technology infrastructure are major organizational mechanisms that needed to be put in place to complement the people's orientation for effective implementation (Al-Mashari \& Zairi, 1999).

In focusing this study, the operationalisations of the CSFs of BPR (Table 1) were distilled from various articles and empirical research on BPR implementations. They were then categorised into a number of subgroups, similar to AlMashari \& Zairi (1999), representing various dimensions of change related to BPR implementation. These dimensions are as follows: (1) Change of management systems and culture; (2) Management competency and support; (3) 
Organisational structure; (4) Project planning and management; and (5) IT infrastructure. In summary, operationalisation of the CSFs of BPR model in this study is tabulated in Table 1, depicting the critical success factors of business process re-engineering. The relationship between the various constructs and operational and organizational performances are depicted in the conceptual model, shown in Figure 1.

The conceptual model of the current study is drawn from two streams of research, i.e. operations management literature and organizational performance literature. Figure 1 illustrates the conceptual model with the arrows depicting the hypothesized relationships between the constructs. These relationships deal with three sets of hypotheses: (1) The effects of the BPR CSFs on the operational performance (primary measures); (2) The relationship between the BPR CSFs and the organizational performance (secondary measures); and (3) The influence of the primary measures (as expressed by the operational performance) on the secondary measures (as expressed by the organizational performance).

\section{Table 1: The measure of CSFs of BPR}

\begin{tabular}{|c|c|}
\hline Variable & Description of factors \\
\hline A1 & $\begin{array}{l}\text { There is a review of motivations, compensation and rewards Systems to ensure successful introduction of new work Processes } \\
\text { and job structures }\end{array}$ \\
\hline A2 & There is adequate education of staff and other stakeholders regarding the BPR concepts \\
\hline A3 & Staff are allowed to set their goals, monitor their own performance, in relation to their work targets \\
\hline A4 & Staff, teams and other stakeholders are openly and actively involved throughout the BPR stages \\
\hline A5 & $\begin{array}{l}\text { There is effective communication during the BPR Process to ensure understanding of the various cultural and Organizational } \\
\text { changes }\end{array}$ \\
\hline A6 & $\begin{array}{l}\text { Our Organization understands and conforms to the newly established culture, rules and work processes due to the introduction } \\
\text { of BPR }\end{array}$ \\
\hline A7 & $\begin{array}{l}\text { There is adequate training and capacity development for staff, teams and other stakeholders in interpersonal, change and } \\
\text { conflicts management, TQM Implementation and process analysis techniques skills to ensure successful BPR implementation }\end{array}$ \\
\hline A8 & Our Organisation prepares staff, Teams and other stakeholders to respond positively to BPR changes \\
\hline B1 & There is commitment and support from the top Management during the BPR implementation process \\
\hline $\mathrm{B} 2$ & Leadership is effective and Creative in taking decisions thus providing a clear vision for the future \\
\hline B3 & $\begin{array}{l}\text { There are re-engineering champions, leaders and project managers who continually push and coordinate BPR efforts throughout } \\
\text { our Organisation }\end{array}$ \\
\hline B4 & There is effective anticipation and planning for risks associated with BPR in our organization \\
\hline B5 & $\begin{array}{l}\text { There is constant BPR evaluation and risk assessment to ensure Successful changes (e.g. risk associated with loss of personnel, } \\
\text { loss of earnings, structural changes etc.) }\end{array}$ \\
\hline B6 & $\begin{array}{l}\text { Sufficient authority and knowledge, and proper interaction with all parts in the change process are encouraged in our } \\
\text { Organisation }\end{array}$ \\
\hline $\mathrm{C} 1$ & New organizational structures are created to determines BPR teams composition and process effectiveness \\
\hline $\mathrm{C} 2$ & $\begin{array}{l}\text { BPR teams and Champions are experienced, credible, innovative and well empowered to handle all aspect of the organizational } \\
\text { needs }\end{array}$ \\
\hline $\mathrm{C} 3$ & $\begin{array}{l}\text { There are appropriate job descriptions and allocation of responsibilities/authority resulting from BPR implementation in my } \\
\text { Organisation }\end{array}$ \\
\hline $\mathrm{C} 4$ & BPR Teams is made up of people from both inside and outside our Organisation \\
\hline $\mathrm{C} 5$ & When new processes and structures are designed, our jobs become Process-based rather than task-based \\
\hline C6 & There is emphasis on designing and implementing an adequate organizational human resources infrastructure \\
\hline D1 & There is effective planning and use of project management techniques in smoothing the flow of process redesign \\
\hline D2 & There is effective process redesign and Performance appraisals as a result of BPR implementation efforts \\
\hline D3 & Our Organisation carefully aligns our corporate strategy and continuous improvement techniques (i.e. TQM with BPR strategy \\
\hline D4 & There is adequate allocation and distribution of resources needed for the BPR effort \\
\hline D5 & There are experienced consultants and experts to assist BPR implementation efforts \\
\hline D6 & BPR mission and vision that direct both long-term and day-to-day operations are clearly stated to all employees \\
\hline E1 & There is adequate investment in information technology infrastructure to support BPR projects \\
\hline E2 & There is alignment of information technology infrastructure with BPR strategy in my Organisation \\
\hline E3 & There is constant control and measurement of information technology infrastructure effectiveness \\
\hline E4 & There is effective integration of organizational information systems (i.e. data integration and communication networking) \\
\hline E5 & There is adoption of information systems that uses the latest technologies/ techniques \\
\hline E6 & $\begin{array}{l}\text { There is an effective use of software tools and information capabilities to enhance organization performance (productivity, } \\
\text { growth , profitability etc.) }\end{array}$ \\
\hline
\end{tabular}

Source: Adapted from Khong \& Richardson (2003), Al-Mashari \& Zairi (1999), Davenport (1993), Hammer \& Champy (1993) 


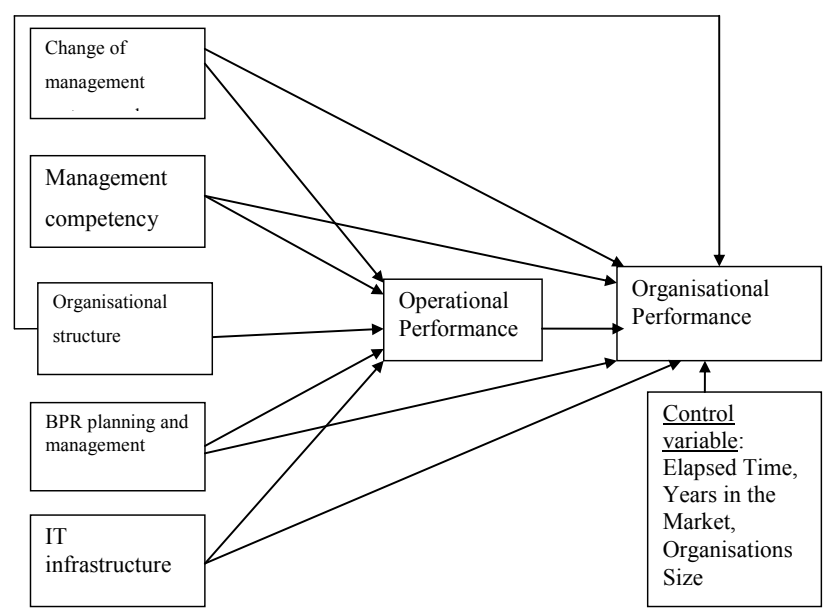

Figure 1: Proposed model for the effects of BPR efforts on performance

\section{Business performance measures}

Several empirical studies have been conducted to establish the link between BPR effort and organizational performance (Smith, 2003; Khong \& Richardson, 2003; Ahmed et al., 2007; Bontis et al., 2000). The results of these studies indicated that there are various measures, i.e. organizational performance, corporate performance, business performance, operational performance, financial and non-financial performance, innovation performance, and quality performance. As adapted in this study, Asikhia (2010), Ahmed et al. (2007), Guenzi \& Troilo (2007), Khong \& Richardson (2003), Bontis, Chua \& Richardson (2000) and Bhote (1996) measured performance in two dimensions: operational performance and organizational performance. Operational performance reflects the performance of internal operation of the company in terms of cost and waste reduction, improving the quality of products, improving flexibility, improving employee relations, operating procedures; and productivity improvement (Salaheldin, 2009). They are considered as primary measures because they follow directly from the actions taken during the implementation of BPR, while organizational performance measured by financial measures such as growth and profitability, and non-financial measures such as sustainable competitive advantage and customer services. They are called secondary measures because they are consequences of BPR implementation (Salaheldin, 2009). The measures of performance are depicted in Table 2.

\section{Table 2: The measure of performance}

\begin{tabular}{|c|c|}
\hline Variable & Key factors manifesting Business Performance \\
\hline & OPERATIONAL: \\
\hline F1 & Our organisation's operating cost reduces relative to competition \\
\hline $\mathrm{F} 2$ & Management is satisfied with the level of waste reduction in our organization \\
\hline F3 & There is a general improvement in the quality of products relative to competition \\
\hline F4 & Management is satisfied with Improving flexibility in production and work processes \\
\hline F5 & Management is satisfied with improved employee participation and morale \\
\hline \multirow[t]{2}{*}{ F6 } & Management is satisfied with improved products and services quality, process and productivity, and reduced errors/defects \\
\hline & ORGANISATIONAL: Profitability Dimension \\
\hline G1 & Our Organisation's Net profit position improves relative to competition \\
\hline G2 & Management is satisfied with return on corporate investment \\
\hline G3 & Management is satisfied with return on sales \\
\hline G4 & Our Returns on investment (ROI) position improves relative to competition \\
\hline G5 & Our Organisation's Return on Assets (ROA) position improves relative to competition \\
\hline \multirow[t]{2}{*}{ G6 } & Our Organisation's Financial liquidity (cash) position improves relative to competition \\
\hline & Growth Dimension \\
\hline G7 & Our deposits growth position improves relative to competition \\
\hline G8 & Management is satisfied with our deposits growth rate \\
\hline \multirow[t]{2}{*}{ G9 } & Our Market share gains relative to competition \\
\hline & Sustainable Competitive Advantage Dimension \\
\hline G10 & $\begin{array}{l}\text { Our competitive advantage in BPR implementation is difficult for competitors to copy because it uses resources that we only } \\
\text { have access to. }\end{array}$ \\
\hline G11 & $\begin{array}{l}\text { It took our Organisation time to build the competitive advantage and competitors would find it time-consuming to follow a } \\
\text { similar route. }\end{array}$ \\
\hline \multirow[t]{2}{*}{ G12 } & $\begin{array}{l}\text { Possession of unique proprietary technology, tacit know-how, and firm reputation/ image induces our companies propensity to } \\
\text { transfer new management techniques }\end{array}$ \\
\hline & Customer Services Dimension \\
\hline G13 & Market research is conducted to discover customers expectation and changes in customer satisfaction \\
\hline G14 & There is a record of customers' requests, complaints and transactions for future reference \\
\hline G15 & Customers' complaints, lost customer analysis and feedback are used to improve the products/ services \\
\hline G16 & Customers are satisfied with the customer service and Customers relationship management of my organization \\
\hline
\end{tabular}

Source: Khong \& Richardson (2003); Bontis, 1998; Bontis et al. 2000; Bhote, 1996; Guenzi \& Troilo, 2007; Asikhia, 2010 
In general, there is a common assumption in the literature that the BPR CSFs have a positive impact on the operational performance (Ahmed et al., 2007; Khong \& Richardson, 2003; Peppard \& Fitzgerald, 1997). They indicated that BPR firms outperform non-BPR firms in operational performance such as reduction in production costs, increasing productivity, improving flexibility, improving employee relations, operating procedures and improving the quality of products. However, to investigate the previous mentioned relationship, the following hypotheses are therefore proposed:

$H_{1} A$ : change of management system and culture has positive relationship with operational Performance

$H_{2} A$ : management support and competence has positive relationship with operational Performance

$H_{3} A$ : Organisational structure has positive relationship with operational performance

$H_{4} A$ : Project planning and management has positive relationship with operational Performance

$H_{5} A$ : IT infrastructure has positive relationship with operational performance

The relationships between BPR practices and organizational performance have been addressed in several studies (Ozcelik, 2010; Abdolvand et al., 2008; Adeyemi. \& Aremu, 2008; Ahmed et al., 2007; Khong \& Richardson, 2003; Peppard \& Fitzgerald, 1997). They indicated a positive association between BPR practices and improved organizational performance. In other words, the results of those studies demonstrated the crucial role of BPR practices in enhancing the organizational performance, i.e. financial performance and non-financial performance (Salaheldin, 2009). Therefore, it is hypothesized that:

$H_{1} B$ : change of management system and culture has positive relationship with organizational Performance

$\mathrm{H}_{2} \mathrm{~B}$ : management support and competence has positive relationship with organizational Performance

$H_{3} B$ : Organisational structure has positive relationship with organizational performance

$\mathrm{H}_{4} \mathrm{~B}$ : Project planning and management has positive relationship with organizational Performance

$H_{5} B$ : IT infrastructure has positive relationship with organizational performance

Lastly, this study attempts to investigate the effects of the primary measures (as expressed by the operational performance measures) on the secondary measures (as expressed by the organizational performance). As emphasized by Ozcelik (2010), Abdolvand et al. (2008), and Khong \& Richardson (2003), the operational performance has a positive correlation with overall organizational performance. One possible explanation could be due to the success of BPR implementation as measured by operational measures such as producing high quality products, speed of delivery, high flexibility, switching costs, safety, waste reduction, resource conservation and high productivity would lead to success in the secondary measures, i.e. financial and non-financial measures (Peppard \& Fitzgerald, 1997; Ahmed et al., 2007; Salaheldin, 2009). Therefore, it is hypothesized that:

$H_{6}$ : Operational performance has positive relationship with organizational performance

\section{Research methodology}

Surveys, via the use of questionnaire, were the primary source of data collection for this research. As Khong (2005) claims, survey research is an appropriate method to generalize from a sample to a population, allowing in this sense, to establish inferences over the entire population. The population consists of senior and Management staff in the exploration and production sector of the Nigerian oil and gas industry. These levels of staff have been used in previous research (Ozcelik, 2010; Siha \& Saad, 2008; Khong \& Richardson, 2003), based on the premise that they were among the most knowledgeable informants on BPR projects and the derived success in their respective organizations. From a time dimension, this research adopts a one-time cross-sectional perspective, while the unit of analysis is the firm.

\section{The construction of the questionnaire and its appropriateness to the study}

A personally-administered questionnaire was primarily adapted from earlier studies (Asikhia, 2010; Guenzi \& Troilo, 2007; Khong \& Richardson, 2003; Khong \& Richardson, 2003; Bontis et al., 2000; Al-Mashari \& Zairi, 1999; Bontis, 1998; Bhote, 1996; Davenport, 1993; Hammer \& Champy, 1993) and it was modified to be consistent with the research context, respondents' orientation and understanding. All the items in the questionnaire were measured with a five-point Likert scale ranging from 1 to 5, where " $1=$ strongly disagree, $2=$ Disagree, $3=$ neither disagree nor agree, $4=$ Agree, $5=$ strongly agree and $\mathrm{n} / \mathrm{a}$ is "not applicable' or 'no comments". This was done to ensure consistency and the ease of data computation (Ozcelik, 2010). This scale was also pre-tested several times by three professors in Management studies and ten experts in BPR implementation, specifically in the Nigerian oil and gas context and it was found to be valid on the basis of this study.

In the questionnaire, participants were asked to answer three important sections; section A with regards to the demographic data, section B, CSFs of BPR and section $\mathrm{C}$ contains items measuring the business performance (operational and organizational performances). In items measuring successful BPR (CSFs) implementation, respondents were asked to rate the degree of usefulness of 
32 variables (Table 1) in association with their company's BPR strategies. In performance measures, they were asked to rate 6 and 16 variables (Table 2) in relation to their companies' operational and organizational performances respectively. The items used to measure the control variables (firm size, years in the market and elapsed time) incorporated in the proposed model have been corroborated by and adopted from previous studies. Nevertheless, each item was discussed and evaluated by five experts in BPR implementations in the Nigerian oil and gas industry. Years in the market was registered as a continuous variable measuring the period from firm establishment through the point of data collection (Buday, 1993). In addition, firm size was also registered as a continuous variable measuring the number of employees (Ozcelik, 2010; Siha \& Saad, 2008). Lastly, elapsed time was registered as a continuous variable measuring the period since the implementation of the BPR efforts (Ozcelik, 2010; Siha \& Saad, 2008; Khong \& Richardson, 2003).

The pre-test also included a pilot study, which was conducted to get insights into the essential CSFs of BPR implementation and its effects on organizational performance, in the Nigerian context. Consequently, convenience sampling techniques was used to select and investigated two Nigerian oil and Gas Companies, Addax Petroleum Development Company Ltd. (multinational company) and Monipulo Limited (local company) which have adopted and implemented BPR, at the pilot stage of this study. The data from the pilot test was processed and analysed. 160 questionnaires were administered, out of which 94 questionnaires were returned. 8 questionnaires were discarded from analysis due to omission of vital variables by respondents. In all 86 (53\% response rate) questionnaires were accepted and analysed at the pilot stage.

\section{Reliability of the questionnaire}

Reliability analysis is conducted in order to measure the internal consistency of variables, measured by interval scale items, in a summated scale (Hair, Anderson, Tatham \& Black, 1998). In this paper, the summated scales are CSFs of BPR and business performance (operational and organizational). Based on the data collected during the pilot stage, Cronbach's alpha scores were computed for each construct (change of management system and culture, management support and competence, organizational structure, project planning and management, IT infrastructure, operational performance and organizational performance measures) to measure the internal consistency and to indicate how different items can reliably measure the construct.

Table 3: Summary of test result-reliability analysis

\begin{tabular}{|c|c|c|c|c|}
\hline Constructs & $\begin{array}{l}\text { Number of } \\
\text { questionnaire items }\end{array}$ & $\begin{array}{l}\text { Cronbach's } \\
\text { Alpha (mean) }\end{array}$ & $\begin{array}{l}\text { Composite } \\
\text { Reliability(CR) }\end{array}$ & $\begin{array}{l}\text { Average Variance } \\
\text { Extracted (AVE) }\end{array}$ \\
\hline Change of management system and culture & 8 & 0.732 & 0.713 & 0.622 \\
\hline Management support and competence & 6 & 0.807 & 0.715 & 0.798 \\
\hline Organizational structure & 6 & 0.811 & 0.811 & 0.715 \\
\hline Project planning and management & 6 & 0.889 & 0.776 & 0.724 \\
\hline IT infrastructure & 6 & 0.802 & 0.733 & 0.754 \\
\hline Operational performance & 6 & 0.753 & 0.705 & 0.713 \\
\hline Organizational performance & 16 & 0.705 & 0.711 & 0.689 \\
\hline
\end{tabular}

Hair et al. (1998) pointed out that a reliability coefficient of 0.7 and above can be considered "adequate", depending on the questions. In this research, all scales have reliability coefficients greater than 0.7 (see Table 3 ). Thus, the scales used in this research could be considered as reliable. In addition, factoring method used was "Principal Components", applying an Orthogonal Varimax rotation with Kaiser's normalization. Based on these conditions, 7 Factors were obtained (Kaiser's criterion of retaining factors with eigenvalues greater than 1), which was consistent with the 7 constructs used in the proposed model (Khong \& Richardson, 2003).

During the main study, a multi-stage sampling technique was adopted. In a large scale survey, the size of the sampling frame will be too large which leads to more time and cost of the study. In such study, multi-stage sampling technique helps designing a smaller sampling frame which will make the study practicable in terms of cost and time (Abdolvand et al., 2008). The first stage entailed the use of clustering and purposive sampling techniques in selecting the participating companies. In cluster sampling, companies with the same characteristics were grouped together thus there were two clusters, Multinationals and Local Companies. Multinational companies are companies with foreigners as majority stakeholders, while Local companies are oil and gas companies with Nigerians as majority stakeholders. Then purposive sampling of the companies was done to ensure that the two clusters were adequately represented. In the "Exploration and Production, Multinationals" cluster, four companies were selected using random sampling method, while in the "Exploration and Production, Local" cluster, four companies were also selected randomly. Consequently, Chevron petroleum (Nig.) Limited, Mobil Producing Nigeria unlimited, Shell Petroleum Development Company Ltd., Nigeria Agip Oil Company (Exploration and Production, Multinationals) and Atlas Petroleum International Limited, Dubri Oil Company Limited, Express Petroleum and Gas Ltd., Amni International Petroleum Development Company Limited (Exploration and Production, Local) were selected respectively. These companies selected adequately 
represented BPR perspective in the Nigeria context, since all the eight companies accounted for over 70 percent of Nigeria daily crude oil production (Osu, 2011).

The second stage involved the use of proportionate sampling method in allocating copies of questionnaire to the participating companies. The use of proportionate sampling was justified due to the differences in size and structure of the participating companies (Khong, 2005). The last stage involved the use of random sampling method, in selecting the final respondents for each oil and gas company, based on the total allotted questionnaires. Overall, the total questionnaires were settled at 650 . Consequently, with the help of two trained Research Assistants, a total of 650 questionnaires were administered to the respondents based on the allotted questionnaires for each participating Oil and Gas Company, after obtaining necessary authorization from the management of these companies (Khong, 2005). A total of 420 questionnaires were returned to the researcher within one month. Out of the 420 questionnaires, 18 questionnaires were discarded due to incorrect fillings by the respondents. In all 402 usable questionnaires (62\% response rate) were analysed. Using SPSS 15.0 (Statistical Package for Social Sciences), the data from the copies of questionnaire were analysed using the following methodologies in sequential order: factor analysis, and multiple regression analysis.

\section{Results and discussion of findings}

\section{Factor analysis}

The purpose of factor analysis, in this study, was to reduce the 54 variables, of which 32 were manifesting successful BPR and 22 manifesting business Performance (operational and organizational performances), to a more manageable set of factors (Hair et al., 1998). Using SPSS 15.0, the results of this factor analysis, via confirmatory factor analysis, with the assumption of extracting via principal components method and rotating via varimax, are shown in Tables 5 .

In order to define which factors manifesting successful BPR and business performance (operational and organizational performances), confirmatory factor analysis method was used; and it is common that variables with high factor loadings will be assigned to describe the respective factors, while variables that have low loadings on respective factors are constrained to zero (Hair et al., 1998). The component matrix for successful BPR (CSFs of BPR) and business performance (operational and organizational) revealed only seven significant factors, that is, Factor 1, 2, 3, 4, 5, 6 and 7
(Table 5), representing each of the constructs. The seven factors were extracted. Consequently, factors 2,3,4,6 and 7 manifest change of management system and culture, organizational structure, IT infrastructure, management support and competence, and project planning and management respectively (CSFs of BPR); while factors 1 and 5 manifest organizational performance and operational performance respectively. However, since variables with factor loadings above 0.70 were deemed to represent the various constructs, these variables with higher factor loadings were used to test the underline hypotheses, via multiple regression analysis (Hair et al., 1998).

\section{Overall model fit}

Covariance analysis using AMOS 18.0 was used to evaluate the factor structure of the Critical Success Factors of Business Process Re-engineering, Operational and Organizational Performance items of constructs in a confirmatory factor analysis model.

AMOS 18.0 minimizes a fit function between the actual covariance matrix and a covariance matrix implied by the estimated parameters from a series of structural equations for the confirmatory factor analysis model. These incremental fit indices compare the proposed model with a baseline or null model. The comparative fit index (CFI) (Bentler, 1990) and the Tucker-Lewis index (Hair et al., 1998) suggested that the overall comparative model fit is excellent, $X^{2}=801.21$ and 331 degrees of freedom, $p<0.01$; normed fit index $(\mathrm{NFI})=0.96$; non-normed fit index $(\mathrm{NNFI})=0.95$; comparative fit index $(\mathrm{CFI})=0.97$; root mean square error of approximation (RSMEA) (90\% confidence interval $=0.079)$ and standardized root mean square residual $(\mathrm{SRMR})=0.095$ (Baumgartner \& Homburg, 1996; Hair et al., 1998). Each of these indicators suggested that a good model had been identified, as shown in Figure 2. The loadings of manifest indicators on their respective latent constructs all exceeded Steenkamp's criteria of 0.4 for factor loadings. All coefficients in the confirmatory factor analysis model were statistically significant at $\mathrm{P}<0.05$.

In addition, testing the model fit, the $\mathrm{R}^{2}$ coefficient $=0.4226$, implying that the 5 independent variables (CSFs of BPR) explain $42.26 \%$ of the variance of organizational performance, while the same CSFs of BPR explain 52.22\% of the variance of operational performance. Other fit indices indicate a reasonable fit with We can thus safely conclude that the model is accepted to fit the data and we can continue to analyse the outcome of the hypothesized effects. 


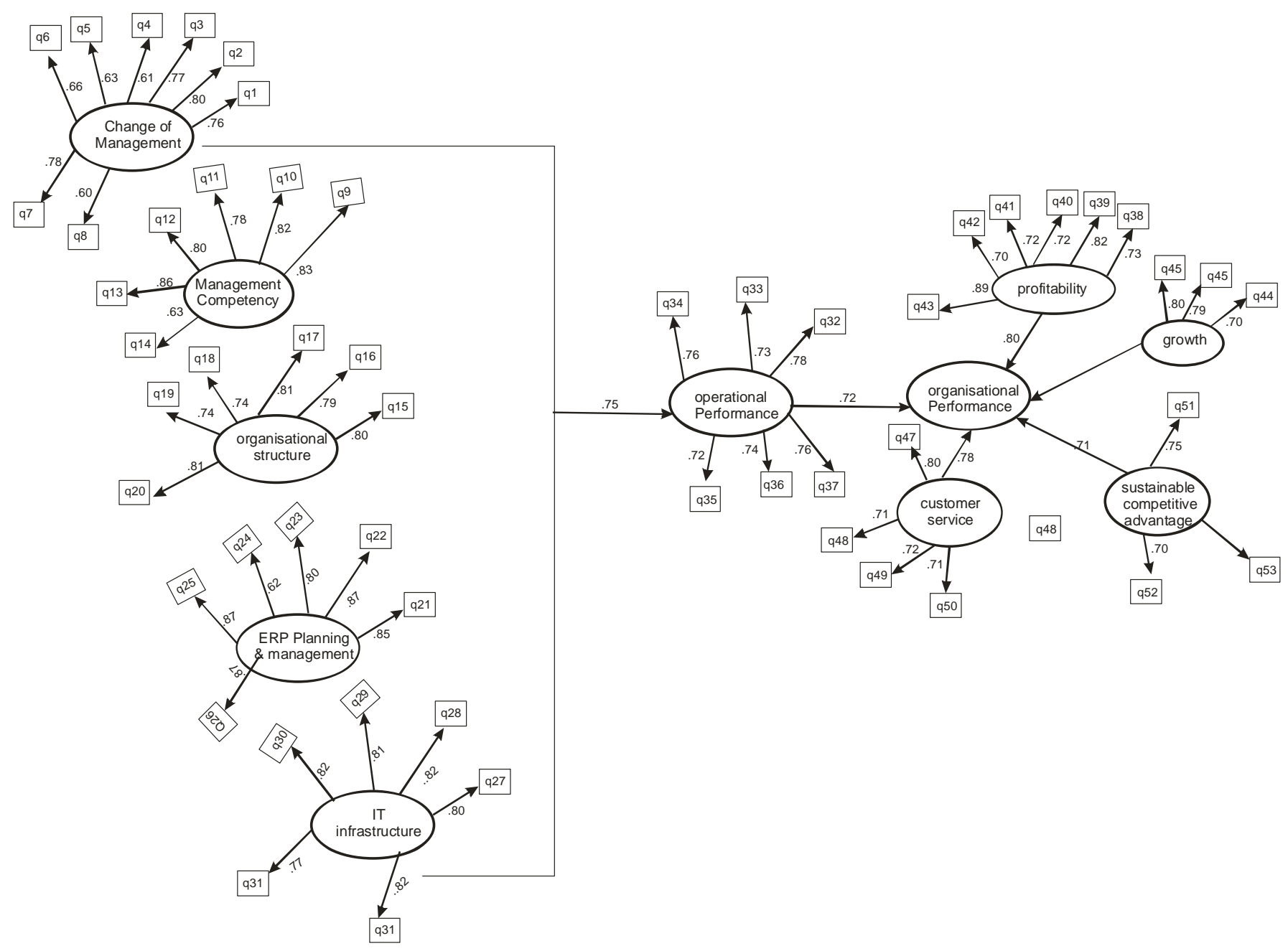

Figure 2: Structural equation modelling for path dependencies of the variables

\section{Multivariate analysis-regression analysis}

After performing factor analysis, regression analysis is a suitable path for analysis; in this study, the underlying hypotheses were analysed using regression analysis. According to Hair et al. (1998), multiple regression analysis is a convenient statistical technique to be used when the researcher requires analysing the relationship between a single dependent variable and several independent variables. However, since a mediating effect (operational performance) was defined in the model, the Path Analysis Technique was applied to test proposed hypotheses. Path Analysis is a regression-based technique widely used for analysing the direct and indirect effects in model encompassing mediating variables (Asteriou \& Hall, 2007). It must follow a three-step regression procedure to assess the hypotheses, as suggested by Baron \& Kenny (1986), Frazier et al. (2004) and Hair et al. (1998):
- $\quad$ Step 1: Regression between Mediator and Independent Variables.

- Step 2: Regression between Dependent Variable and Independent Variables.

- Step 3: Regression between Dependent Variable and Independent Variables plus Mediator.

\section{Hypothesis testing}

In order to examine the relationships between CSFs of BPR (exogenous constructs) and business performance (as represented by operational and organizational performances) of Nigerian oil and gas companies (endogenous constructs), the hypothesized relationships were tested, using multiple regression tool in SPSS (Statistical Package for Social Sciences) 18.0. The results are shown in Table 4. 
Table 4: Testing the hypotheses

a. Step 1: Regression between mediator and independent variables

\begin{tabular}{|c|c|c|c|c|c|c|}
\hline \multicolumn{5}{|l|}{$\begin{array}{l}\mathrm{R}^{2}=0.5222 \\
\text { Durbin Watson }=1.897\end{array}$} & \multicolumn{2}{|c|}{$\begin{array}{l}\text { Sig }<.0001 \\
\text { Operational performance }\end{array}$} \\
\hline $\begin{array}{l}\text { Construct } \\
\text { Association }\end{array}$ & ' $\alpha$ ' level & Beta & $\rho$-value & $\begin{array}{l}\text { Significant } \\
\text { (yes/no) }\end{array}$ & Hypothesis & Validation \\
\hline $\begin{array}{l}\text { Change of management system and culture with } \\
\text { operational performance }\end{array}$ & 0.05 & 0.32 & 0.040 & Yes & Accept H1A & Yes \\
\hline $\begin{array}{l}\text { Management support and competence with operational } \\
\text { performance }\end{array}$ & 0.10 & 0.15 & 0.081 & Yes & Accept H2A & Yes \\
\hline Organizational structure with operational performance & 0.50 & 0.37 & 0.027 & Yes & Accept H3A & Yes \\
\hline $\begin{array}{l}\text { Project planning and management with operational } \\
\text { performance }\end{array}$ & 0.05 & 0.35 & 0.033 & Yes & Accept H4A & Yes \\
\hline IT infrastructure with operational performance & 0.05 & 0.33 & 0.043 & Yes & Accept H5A & Yes \\
\hline
\end{tabular}

\section{b. Step 2: Regression between dependent variable and independent variables}

\begin{tabular}{|c|c|c|c|c|c|c|}
\hline \multicolumn{5}{|l|}{$\begin{array}{l}\mathrm{R}^{2}=\mathbf{0 . 4 2 2 6} \\
\text { Durbin Watson }=2.137\end{array}$} & \multicolumn{2}{|c|}{$\begin{array}{l}\text { Sig }<.0001 \\
\text { Operational performance }\end{array}$} \\
\hline $\begin{array}{l}\text { Construct } \\
\text { Association }\end{array}$ & $\begin{array}{l}\text { ' } \alpha ' \\
\text { Level }\end{array}$ & Beta & $\rho$-value & $\begin{array}{l}\text { Significant } \\
\text { (yes/no) }\end{array}$ & Hypothesis & Validation \\
\hline $\begin{array}{l}\text { Change of management system and culture with } \\
\text { organizational performance }\end{array}$ & 0.05 & 0.38 & 0.004 & Yes & Accept $\mathrm{H}_{1} \mathrm{~B}$ & Yes \\
\hline $\begin{array}{lcc}\begin{array}{l}\text { Management support and competence } \\
\text { organizational performance }\end{array} & \text { with } \\
\end{array}$ & 0.05 & 0.10 & 0.101 & No & Reject $\mathrm{H}_{2} \mathrm{~B}$ & No \\
\hline $\begin{array}{llll}\begin{array}{l}\text { Organizational } \\
\text { performance }\end{array} & \text { structure } & \text { with } & \text { organizational } \\
\end{array}$ & 0.10 & 0.17 & 0.077 & Yes & Accept $\mathrm{H}_{3} \mathrm{~B}$ & Yes \\
\hline $\begin{array}{l}\text { Project planning and management with organizational } \\
\text { performance }\end{array}$ & 0.05 & 0.22 & 0.025 & Yes & Accept $\mathrm{H}_{4} \mathrm{~B}$ & Yes \\
\hline IT infrastructure with organizational performance & 0.05 & 0.25 & 0.015 & Yes & Accept $\mathrm{H}_{5} \mathrm{~B}$ & Yes \\
\hline
\end{tabular}

\section{c. Step 3: Regression between dependent variable and independent variables plus mediator}

$\mathbf{R}^{2}=0.7221$

Durbin Watson $=2.322$

Construct

Association

Change of management system and culture with organizational performance

Management support and competence with organizational performance

Organizational structure with organizational performance

Project planning and management with organizational performance

IT infrastructure with organizational performance

Operational performance with organizational

performance

Elapsed time with organizational performance

Years in the Market with organizational performance

organization Size with organizational performance

Note: $\alpha$ level denotes significant level

\section{Discussion of findings}

Findings based on the survey revealed that successful BPR can positively affect organizational performance. Except for management support and competence $(\beta=0.10, p=0.101)$, the results suggests the positive effects of the CSFs of BPR (Change of management system and culture - $\beta=0.38$, $\mathrm{p}=0.004$; organizational structure $-\beta=0.17, \mathrm{p}=0.077$; project planning and management $-\beta=0.22, p=0.025$; and IT infrastructure - $\beta=0.25, \quad \mathrm{p}=0.015) \quad$ on improved organizational performance in Nigerian oil and gas companies, and were corroborated empirically in this study.

The only surprising result of this study was the inability to corroborate the influence of management support and competency on the improved business performance, as a result of BPR implementation effort in Nigerian oil and gas companies. This unique finding was contrary to many empirical findings (Ascari et al., 1995; Smith, 2003; Khong \& Richardson, 2003; and Ahmed et al., 2007; Talwar, 1993; 
Zairi \& Sinclair, 1995). There are few possible explanations for this result. The first one can be drawn from empirical research by Adeyemi \& Aremu (2008). In this study, it was found that many Nigerian companies often failed to attract the needed personnel or consultants, especially in highly technical industry like the oil and gas. Hence, BPR effort is often characterized by poor management support and competencies needed for its successful implementation (Khong \& Richardson, 2003). The second one can be more related to the findings posted by Smith (2003) and Adeyemi \& Aremu (2008). They assert that Nigeria, and indeed all developing economies, are characterized by lack of effective anticipation and planning for risks associated with BPR efforts.

In addition, the results also suggests the positive effects of the CSFs of BPR (Change of management system and culture - $\beta=0.32, p=0.040$; management support and competence - $\beta=0.15, p=0.081$; organizational structure $\beta=0.37, \quad p=0.027$; project planning and management $\beta=0.35, p=0.033$; and IT infrastructure- $\beta=0.33, p=0.043$ ) on operational performance (Step 2) in Nigerian oil and gas companies, and were also corroborated empirically. Validation of $\mathrm{H}_{6}$ : was done based on Baron \& Kenny (1986) established conditions for mediation: (1.) the independent variables must affect the mediator in Step 1 (Table $4 \mathrm{a}$ confirms this condition). (2.) The independent variables must be shown to affect the dependent variable in Step 2 (Table $4 \mathrm{~b}$ confirms this condition). (3.) The mediator must affect the dependent variable in the Step 3 (Table 4c confirms this condition). (4.) The effect of the independent variables on the dependent variable must be less in the Step 3 than in the Step 2 (this was also confirmed by the difference between Tables $4 \mathrm{~b}$ and $4 \mathrm{c}$ ). Meaning that, operational performance has significant positive relationship with organizational performance $(\beta=0.15, p=0.0001)$, based on the data set of this study. Thus, this finding confirmed a previous study that investigated the relationship (Smith, 2003; Khong \& Richardson, 2003). This finding shows the nature of the relationship between BPR effectivenessoperational performance- and the success of BPR organizational performance. In other words, operational performance measures should be brought into the proactive measurement loop. They should be the starting point of the measurement cycle, particularly if BPR managers are really interested in reaping the full benefits of BPR implementation. However, only organizational structure experienced full mediation

All results are significant at $\mathrm{p}<0.05$, except for the relationships between Organizational structure and organizational performance, as well as, management support and competence and operational performance, which were validated at $\alpha=0.10$ level of significance. In summary, these results indicate that all the hypotheses, except the mediating effects of organizational structure and the relationship between management support and competence and organizational performance, were supported and validated by this study. This implied that positive and significant relationships exist between CSFs of BPR and business performance (operational and organisational performances) variables of the Nigerian oil and gas companies. In summary, it is pervasive that successful BPR implementation should result in positive business performance.

In relation to other studies, a positive and significant relationship obtained in this study agrees with the findings of Peppard \& Fitzgerald (1997), Ascari et al. (1995), Smith (2003), Adeyemi \& Aremu (2008) and Ahmed et al. (2007). The study also supports Ascari et al. (1995) and Ozcelik (2010) premise that improved processes, structures and technology reduces a firm's risk of failure in BPR effort, hence, a positive relationship with improved customer service management.

Regarding the influence of control variables, this study corroborates the significant role $(\beta=0.109, \mathrm{p}=0.021$; at 0.05 level of significance) of the elapsed time control variable in the model (Table 4c), demonstrating the importance of controlling for its effects. This study is consistent with the Ozcelik (2010) and Siha \& Saad (2008) studies, where it was suggested that, the longer the time elapsed, the more comfortable employees are with the BPR effort and therefore, the better the results achieved. Hence, time is a critical requisite for extracting value from BPR efforts (Khong \& Richardson, 2003). On the other hand, different findings were observed as regards the influence of the other control variables. Findings suggest that Years in the Market and organization Size are not determinants of BPR's improved business performance. This findings might be due to the fact that those variables (Years in the Market and organization Size) were not crucial in the context of BPR implementation in the oil and gas sector of a developing nation, like Nigeria. This industry is usually characterized by the proliferation of small indigenous companies competing with the established multinational corporation (Al-Mashari \& Zairi, 1999).

\section{Conclusion and implications for practice}

This study was aimed at identifying the critical success factors of BPR implementation and to evaluate their effects on the primary measures as expressed by the operational performance and the secondary measures as expressed by the organizational performance in the Nigerian oil and gas industry. Using the framework from Khong \& Richardson (2003), factors manifesting Business Performance (operational and organizational performances) were regressed on the Critical Success Factors (CSFs), manifesting successful BPR. Findings based on the survey revealed that successful BPR can positively affect business Performance of Nigerian Oil and Gas Companies. The results further suggest the influence of successful BPR towards improving business performance sufficiently $(\mathrm{p}=$ 0.0001). However, with the exception of management support and competence, the influence of change of management system and culture, organizational structure, project planning and management and IT infrastructure on the BPR success (improved business performance) of oil and gas companies were all corroborated empirically. 


\section{Theoretical implications}

This study seems to be among the few examining the success of BPR, and the related critical success factors, in the perspective of how organizations fare after implementing BPR. The notion of BPR success was analysed explicitly by assessing the business value derived from implementing BPR. This gap was originally positioned as a critical area for future research by Al-Mashari \& Zairi (1999: 105). Another contribution of this study is the measurement of business performance, which was not limited to or focused on financial metrics, but encompasses diverse business indicators and perspectives, like profitability, growth, customer services and sustainable competitive advantage. Khong \& Richardson (2003) specifically identified this gap in the literature. This is on the premise that many researchers often use objective measures such as turnover and profit as a form of measuring enterprise/firm business performance. However, according to Khong \& Richardson (2003), perceived measures can replace objective measures of business performance. In addition, this study seems to be one of the few that aims at investigating BPR's success in a developing economy, like Nigeria, by proposing a model and attempting to validate it empirically. Lastly, Ahmed et al. (2007), contends the stringent necessity to provide a model that amalgamates BPR enablers with BPR effectiveness and BPR success. Hence, this study integrates the CSFs of BPR practices, with operational and organizational performances as related drivers of the effectiveness and success of BPR practices in a developing economy, like Nigeria. Very few studies have been performed to investigate and understand this issue. Therefore, the research can make a useful contribution. In addition, this study offers a theoretical model that can be considered as a step forward in developing an integrated model toward investigating the relationship between CSFs of BPR, BPR effectiveness as expressed by the operational performance and BPR success as expressed by the organizational performance and might serve as a basis for future research. Finally, this research adds to the body of knowledge by providing new data and empirical insights into the relationship between the CSFs of BPR practices and operational and organizational performances of oil and gas companies in Nigeria.

\section{Managerial implications}

Nigerian oil and gas companies should consider BPR as an innovative tool for improving operational and organizational performance in today's dynamic business environment. The measurement model provides predictive implications on improved operational performance, as well as its moderating influence on organizational performance, given the activities of critical factors manifesting successful BPR. Moreover, the corroborated findings provide valuable implications for practice. This study is expected to provide specific direction to companies contemplating a BPR programme, hence, the study is expected to be beneficial to Nigerian oil and gas companies and other Nigerian companies alike, policy makers in private and public sectors of the Nigerian economy. It will also explore imperatives for successful implementation. Lastly, the study emphasizes the need to link operational performance to organizational performance to achieve the success of BPR implementation. Hence, management/managers of oil and gas companies should be aware of the intermediating effects of operational performance. This is on the premise that BPR-related financial and non-financial performance (organizational performance) could only be enhanced by improving operational performance in the first place.

However, this research is subject to the normal limitations of survey research. The study is using perceptual data provided by senior and management staff which may not provide clear measures of performance. However, this can be overcome using multiple methods to collect data in future studies. In addition, since only one perspective in each organization was collected - senior and management staff responsible/ actively participated in the BPR implementation process, it is not unreasonable to claim that a method bias may limit the research findings. But even if the constructs measured were conceived as "perceptual" ones identified by a rater (senior and management staff), additional guidelines might be used in future studies to minimize this potential limitation, including: the use of different methods to measure the independent versus dependent variables. 
Table 5: Results of factor analysis for CSFs and Business performance

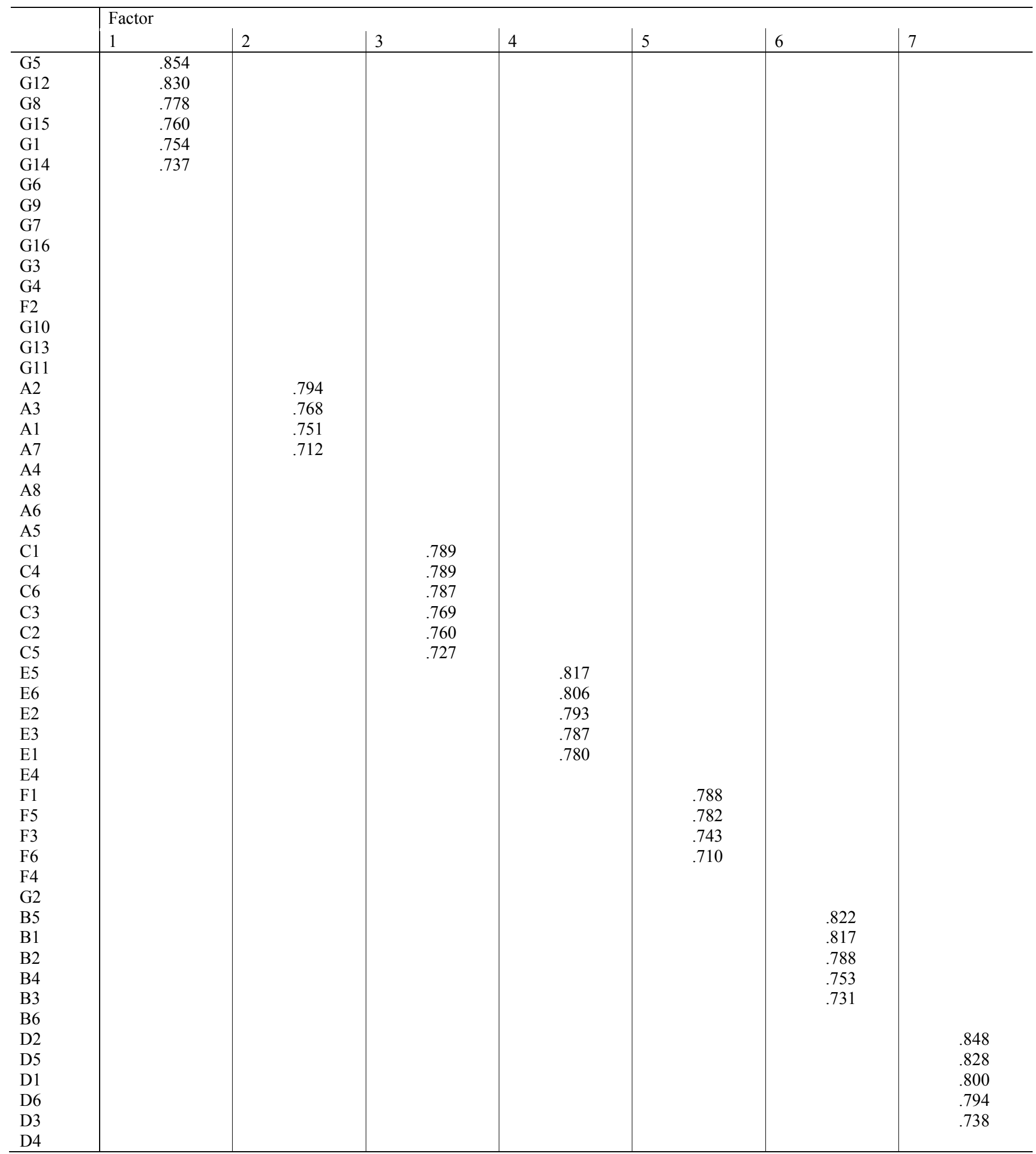

Extraction Method: Principal Component Analysis. Rotation Method: Varimax with Kaiser Normalization. Rotation converged in 7 iterations. 


\section{References}

Abdolvand, N. Albadvi, A \& Ferdowsi, Z. 2008. 'Assessing readiness for business process reengineering', Business Process Management Journal, 14(4): 497-511.

Adeyemi, S. \& Aremu, M.A. 2008. 'Impact assessment of business process reengineering on organizational performance', European Journal of Social Sciences, 7(1 ):115-125.

Aggarwal, S. 1998. 'Re-engineering: A breakthrough or little new?' Journal of Socio-Economic Planning Science, 32(2):155-67.

Ahmed, H., Francis, A. \& Zairi, M. 2007. 'Business process reengineering: Critical success factors in higher education', Business Process Management Journal, 13(3):451-469.

Al-Mashari, M. \& Zairi, M.1999. 'BPR implementation process: An analysis of key success \& failure factors', Business process Management Journal, 5(1):87-112.

Al-Mashari, M. Irani, Z. \& Zairi, M. 2001. 'Business process reengineering: A survey of international experience', Business process Management Journal, 2(4):437-455.

Ariyachandra, T.R., \& Frolick, M.N. 2008. 'Critical success factors in business performance management - striving for success', Information Systems Management, 25(2):113-120.

Ascari, A., Rock, M. \& Dutta, S. 1995. 'Reengineering and organisational change: Lessons from a comparative analysis of company experience', European Management Journal, 13(1):1-30.

Asikhia, O. 2010. 'Strategic marketing orientation and performance: A case for synergistic merger effects of Nigerian banks', European Journal of Scientific Research, 42(2):268-289.

Asteriou, D. \& Hall, S.G. 2007. Applied econometrics: A modern approach. (Revised Edition), NY: Palmgrave Macmillan.

Bandara, W., Gable, G., \& Rosemann, M. 2005. 'Factors and measures of business process modelling: Model building through a multiple case study', European Journal of Information Systems, 14(4): 347-360.

Baron, R., Kenny, D. 1986. 'The moderator-mediator variable distinction in social psychological research: Conceptual, strategic, and statistical considerations', Journal of Personality and Social Psychology, (51), 1173-1182.

Baumgartner, H., \& Homburg, C. 1996. 'Applications of structural equation modelling in marketing and consumer research: A review', International Journal of Research in Marketing, 1(13):139-161.

Bentler, P.M. 1990. 'Comparative fit indexes in structural models', Psychological Bulletin, 107:238-46.

Berrington, C.L. \& Oblich, R.L. 1995. 'Translating business reengineering into bottom-line results', Industrial Engineering, 27(1):24-27.

Bhatt, G.D. 2000. 'Exploring the relationship between information technology, infrastructure and business process re-engineering', Business Process Management, 6(2):139-163.
Bhote, K.R. 1996. Beyond customer satisfaction to customer loyalty: The key to greater profitability. Dublin: Lafferty Publication.

Bontis, N. 1998. 'Intellectual capital: An exploratory study that develops measures and models', Management Decision, 36(2):6367.

Bontis, N., Chua, C.K. \& Richardson, S. 2000. 'Intellectual capital and business performance in Malaysian industries', Journal of Intellectual Capital, 1(1):85-100.

Buday, R. 1993. 'Reengineering one firm's product development and another's service delivery', Planning Review, 21(2):14-19.

Cabin, R. \& Grant, R.M. 1996. 'Restructuring among the world's largest oil majors,' British Journal of Management, 4(3):212-235.

Davenport, T. 1993. Process innovation: Reengineering work through information technology. Harvard Business School Press, Boston, MA.

Davenport, T.H. \& Short, J.E. 1990. 'The new industrial engineering: Information technology and business process redesign,' Sloan Management Review, Summer:11-27.

Elmuti, D. 2003. The perceived impact of outsourcing on organisational performance', Mid-American Journal of Business, 18(2):33-7.

Frazier, P., Tix, A., Barron, K. 2004. 'Testing moderator and mediator effects in counselling psychology research', Journal of Counselling Psychology, 51(1):115-134.

Guenzi, P. \& Troilo, G. 2007. 'The joint contribution of marketing and sales to the creation of superior customer value', Journal of Business Research, 60(2):98-107.

Hair, J.F., Anderson, R.E., Tatham, R.L. \& Black, W.C. 1998, Multivariate analysis, 5th ed., Prentice-Hall, Englewood Cliffs, NJ.

Hall, J., Rosenthal, J. \& Wade, J. 1993. 'How to make reengineering really work', Harvard Business Review, November/December:119-31.

Hammer, M. 1990. 'Reengineering work: Don't automate, obliterate', Harvard Business Review, 68(4):104-12.

Hammer, M. \& Champy, J. 1993. Reengineering the corporation: a manifesto for business revolution, Harper Business, New York, NY.

Jarrar, Y.F. \& Aspinwall, E.M. 1999. 'Business process reengineering: Learning from organizational experience', Total Quality Management, 10(2):173-86.

Khodakaram, S., Mohammad, A.A. \& Ahmad, G. 2010. 'Interpretive structural modelling of critical success factors in banking process re-engineering', International Review of Business Research Papers, 6(2):95-103.

Khong, K.W. 2005. 'The perceived impact of successful outsourcing on customer service management', Supply Chain Management: An International Journal, 10(5):402-411. 
Khong, K.W. \& Mahendiran, N. 2006. 'The effects of customer service management on business performance in Malaysian banking industry: An empirical analysis', Asia Pacific Journal of Marketing and Logistics, 18(2):111-128.

Khong, K.W. \& Richardson, S. 2003. 'Business process reengineering (BPR) in Malaysian banks and finance companies', Managing Service Quality, 13(1):54-71.

Kotler, P. 2000. Marketing management, 10th ed., Prentice Hall, Englewood Cliffs, NJ.

McAdam, R. 2003. 'Radical change: A conceptual model for research agendas', Leadership \& Organization Development Journal, 24(4):226-235.

Osu, P. 2011. 'Reengineering: Government steps up regulatory compliance in the oil and gas industry', DPR News, 6(2):1-8.

Ozcelik, Y. 2010. 'Do business process reengineering projects payoff? Evidence from the United States', International Journal of Project Management, 28(3):7-13.

Peppard, J. \& Fitzgerald, D. 1997. 'The transfer of culturallygrounded management techniques: The case of business process reengineering in Germany', European Management Journal, 15(4):446-60.

Ranganathan, C. \& Dhaliwal, J.S. 2001. 'A survey of business process reengineering practices in Singapore', Information \& Management, 39(2):125-134.

Ringim KJ, Razalli MR, Hasnan N, 2011. 'Effect of business process reengineering factors on organizational performance of Nigerian banks: Information technology capability as the moderating factor', International Journal of Business and Social Sciences, 2(13):198-201.

Salaheldin, I.S. 2009. 'Critical success factors for TQM implementation and their impact on performance of SMEs', International Journal of Productivity and Performance Management, 58(3):215-237.

Shin, N. \& Jemella, D.F. 2002. 'Business process reengineering and performance improvement: The case of Chase Manhattan Bank', Business Process Management Journal, 8(4):351-363.

Siha, S.M. \& Saad, G.H. 2008. 'Business process improvement: Empirical assessment and extensions', Business Process Management Journal, 14(6):778-802.

Singh, M.D. \& Kant, R. 2008. 'Knowledge management barriers: An interpretive structural modelling approach', International Journal of Management Science and Engineering Management, 3(2):141-150.

Smith, M. 2003. 'Business process design: Correlates of success and failure', The Quality Management Journal, 10(2):38-49.

Talwar, R. 1993. 'Business re-engineering: A strategy-driven approach', Long Range Planning, 26(6):22-40.

Vergidis, K., Tiwari, A., \& Majeed, B. 2008. 'Business process analysis and optimization: Beyond reengineering, IEEE Transactions on Systems, Man, and Cybernetics, Part C: Applications and Reviews, 38(1), 69-82.
Zairi, M. \& Sinclair, D. 1995. 'Business process re-engineering and process management: a survey of current practice and future trends in integrated management', Management Decision, 33(3):316. 